\title{
Arranjos Institucionais e Política Industrial de Defesa: construção de um modelo analítico
}

\author{
Christiano Cruz Ambros \\ Universidade Federal do Rio Grande do Sul
}

\section{Introdução}

Durante o século XX, especialmente em decorrência das duas grandes guerras mundiais e da Guerra Fria, a estrutura do sistema internacional e a dinâmica da produção e transferência de armamentos encorajaram um grande número de Estados a buscarem o desenvolvimento de uma indústria de defesa nacional, como forma de atingir a autossuficiência dos meios materiais para a manutenção de sua soberania. A partir do início dos anos 1980, a dinâmica da globalização econômica começou a transformar radicalmente a produção de armamentos e uma série de fatores foram minando a capacidade dos Estados de equipar suas Forças Armadas com produtos domésticos: o acelerado desenvolvimento tecnológico aumentou a sofisticação dos sistemas de armas e elevou significativamente os custos de desenvolvimento e produção desses armamentos; a diminuição dos orçamentos de defesa e consequente retração dos mercados domésticos forçaram uma reorganização da indústria de defesa global, ocasionando muitas aquisições e fusões de empresas e a emergência de grandes multinacionais; e a internacionalização das cadeias de suprimento.

Frente a esse cenário, países como o Brasil, que se encontram em posições intermediárias da hierarquia internacional de produção de armamentos, enfrentam o chamado trilema de modernização da defesa. O trilema reflete as dificuldades em manter uma produção doméstica de armamentos de maneira economicamente sustentável e tecnologicamente relevante para o cumprimento das missões de suas Forças Armadas sem se tornar excessivamente dependente de fornecedores estrangeiros. A própria razão lógica para existência de uma base industrial de defesa nacional e autônoma é questionada por autores (Hayward, 2009; Finnegan, 2009) que argumentam que os países intermediários não conseguirão acompanhar o rápido desenvolvimento tecnológico e as necessidades orçamentárias exigidas pelos altos custos, e, por tanto, deveriam resignar-se em adquirir sistemas de defesa avançados dos países centrais e aceitar sua dependência.

Entretanto, a experiência de uma série de países intermediários vem mostrando que é possível desenvolver estratégias eficientes para superar o trilema da modernização e desenvolver e sustentar uma base industrial de defesa (BID) nacional. Mais do que apostar somente nas políticas pelo lado da demanda (como aquisições e regulamentações de mercado), experiências internacionais demonstram que é necessário criar e manter políticas pelo lado da oferta (apoio à competitividade e inovação, por exemplo). Além disso, faz-se necessário encarar as políticas de defesa dentro da ótica de políticas públicas, que precisam ser monitoradas e avaliadas periodicamente.

Ainda que as políticas de defesa tenham características específicas que as diferenciem significativamente de outras políticas públicas executadas pelos Estados, mesmo assim é possível avaliá-las a partir da perspectiva dos arranjos institucionais. As políticas de aquisição e as políticas industriais de defesa, por seu caráter intersetorial, se adequam ainda melhor a esse tipo de análise, 
dada a necessidade de se identificar atores e prerrogativas legais em um amplo espectro institucional. Assim, esse artigo tem como objetivo propor um modelo de análise para políticas de aquisição e políticas industriais, utilizando-se do arcabouço teórico e ferramental dos estudos de arranjos institucionais de políticas públicas.

Para tanto, divide-se este artigo da seguinte forma: i) avaliação de como os arranjos institucionais se propõem como uma ferramenta analítica para políticas públicas; ii) identificação das principais características das políticas de aquisição e das políticas industriais de defesa; e, finalmente, iii) proposta de um modelo analítico baseado na perspectiva de arranjos institucionais para analisar políticas industriais de defesa.

\section{Arranjos Institucionais como Ferramenta Analítica}

A questão relacionada à capacidade estatal em formular políticas públicas e às burocracias profissionais que as implementam em um contexto democrático é discutida de maneira sistemática e consistente no livro de 2014 lançado pelo IPEA (Instituto de Pesquisa Econômica Aplicada) e editado por Alexandre de Ávila Gomide e Roberto Rocha C. Pires, intitulado "Capacidades Estatais e Democracia: Arranjos Institucionais de Políticas Públicas". A tese sustentada pelo livro é de que, no atual contexto democrático brasileiro, a capacidade do Estado em atender as demandas da sociedade vai além da constituição da típica burocracia weberiana ${ }^{1}$, profissional e autônoma, e necessita da articulação política dos agentes do Estado para a produção de políticas públicas, dada a existência e funcionamento de instituições representativas, participativas e de controles burocráticos. Para abordar as interações entre instituições democráticas e políticas de desenvolvimento e para chegar às indicações de que o suposto trade-off entre a ação estatal consistente e instituições democráticas fortes não é prevalente, Gomide e Pires (2014) e os diversos autores que contribuíram com análises de diversas políticas públicas brasileiras (como o Bolsa Família, o Programa Minha Casa Minha Vida e a Revitalização da Indústria Naval) desenvolveram novos conceitos e modelos analíticos. Dessa forma, o modelo analítico proposto pelos autores é o do foco nos arranjos institucionais para implementação de políticas públicas.

Assim, o conceito de arranjos institucionais pode ser bem aplicado para analisar a formulação e implementação de Políticas Industriais de Defesa. Gomide e Pires (2014, p. 20) explicam o conceito de arranjos institucionais nas palavras que seguem:

Em torno de cada política se arranjam organizações (com seus mandatos, recursos, competências e instrumentos legais), mecanismos de coordenação, espaços de negociação e decisão entre atores (do governo, do sistema político e da sociedade), além das obrigações de transparência, prestação de contas e controle. Portanto, compreender o processo das políticas públicas requer aprofundar o olhar nos arranjos institucionais que dão sustentação à implementação destas. [...] o conceito de arranjo institucional é entendido como o conjunto de regras, mecanismos e processos que

\footnotetext{
${ }^{1}$ A Teoria de Burocracia na Administração, desenvolvida pelo sociólogo alemão Max Weber, identifica as características das estruturas organizacionais do moderno Estado Nacional que estava se consolidando em sua época. A organização burocrática é caracterizada pelo: caráter legal das normas e regulamentos; caráter formal das comunicações; caráter racional e divisão do trabalho; impessoalidade das relações; hierarquia da autoridade; rotinas e procedimentos; competência técnica e meritocracia; profissionalismo; e previsibilidade de funcionamento.
} 
definem a forma particular como se coordenam atores e interesses na implementação de uma política pública específica. São os arranjos que dotam o Estado de capacidade de execução de seus objetivos. Ou, em outras palavras, são os arranjos que determinam a capacidade do Estado de implementar políticas públicas (grifos meus).

No modelo analítico desenvolvido pelos autores (Gomide e Pires, 2014), a capacidade de um arranjo institucional é compreendida a partir das dimensões técnico-administrativas e políticas. Segundo Gomide e Pires (2014, p. 20), a primeira dimensão "deriva do conceito weberiano de burocracia, contemplando as competências dos agentes do Estado para levar a efeito suas políticas, produzindo ações coordenadas e orientadas para a produção de resultados”. Conforme coloca Schapiro (2014, p. 250), os trabalhos de tradição institucionalista "formularam proposições sobre a relevância (externa) do Estado como agente de coordenação econômica e também destacaram a importância (interna) de sua burocracia econômica e de sua organização profissional para o alcance destas finalidades de coordenação”. Para operacionalizar a capacidade técnico-administrativa, Pires e Gomide (2014, p. 352) utilizam os seguintes critérios: i) a presença de organizações com recursos humanos, financeiros e tecnológicos adequados e disponíveis para a condução das ações; ii) a existência e operação de mecanismos de coordenação (intra e intergovernamentais); e iii) estratégias de monitoramento (produção de informações, acompanhamento e exigências de desempenho). Para os autores (Ibidem, p. 368), "altas capacidades técnico administrativas estão associadas à promoção de altas taxas de execução", ou seja, capacidade de implementação dos objetivos da política pública.

A segunda dimensão trata das habilidades da burocracia do Executivo em construir canais de interlocução e negociação com os diversos atores políticos e sociais, "processando conflitos e prevenindo a captura por interesses específicos" (Gomide e Pires, 2014, p. 20). Enquanto a literatura (Chang, 1994; Evans e Rauch, 1999; Rodrik, 2004) admite como essencial para os processos de desenvolvimento nacional a partir de uma política industrial a existência de burocracias com forte capacidade técnico-administrativa, para Gomide e Pires $(2014$, p. 20) as capacidades políticas das organizações do Poder Executivo também seriam fundamentais para a implementação bem sucedida das políticas públicas voltadas para o desenvolvimento e estariam "associadas à promoção da legitimidade da ação estatal em contextos democráticos, por meio da mobilização da sociedade e da articulação e compatibilização de interesses diversos em torno de plataformas comuns".

No modelo desenvolvido por Gomide e Pires (2014), é importante analisar como os diversos atores políticos e sociais envolvidos na política pública participam da sua formulação e implementação, assim como a representação das diversas parcelas da sociedade afetadas e os instrumentos de controles sobre a administração pública (sejam burocráticos, parlamentares ou judiciais). Dessa forma, o gestor público dentro do arranjo institucional precisa se relacionar, simultaneamente, com três sistemas institucionais distintos para a produção das políticas públicas: o representativo, o participativo e o de controles burocráticos. Especificamente, Pires e Gomide (2014, p. 352) decompõem a capacidade política em três fatores: “i) existência e formas de interações das burocracias do Executivo com os agentes do sistema político-representativo (o Congresso Nacional, seus parlamentares, dirigentes dos governos subnacionais - governadores e prefeitos - e seus partidos políticos); ii) existência e operação efetiva de formas de participação social (conselhos, conferências, ouvidorias, audiências e consultas públicas, entre outros); e iii) atuação dos órgãos de controle (sejam 
eles internos ou externos)". Segundo os autores (Ibidem, p. 368), "altas capacidades políticas estão associadas à alta inovação no processo de execução das políticas”, ou seja, à capacidade de adaptabilidade do arranjo institucional para contribuir com o aprimoramento da política, do seu desempenho e da sua aceitabilidade junto aos atores envolvidos.

De forma sintética, esse modelo analítico é representado na figura abaixo:

Figura 1 - Modelo Analítico de Gomide e Pires

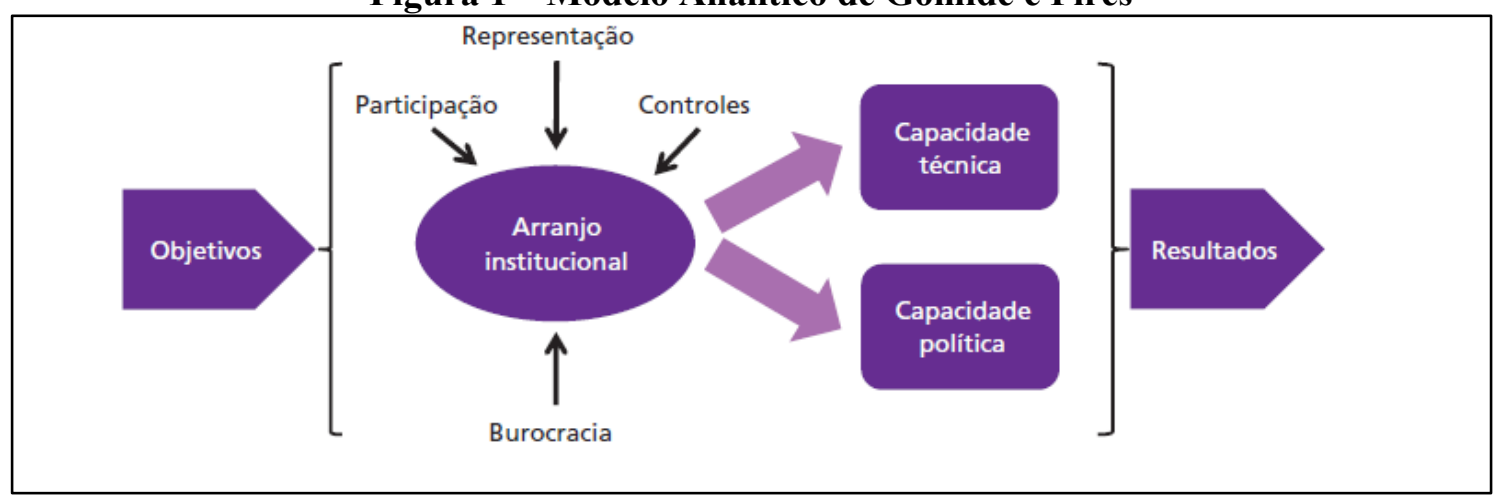

Fonte: Gomide e Pires (2014, p. 21).

Como se pode perceber, a lógica deste modelo analítico é bastante funcionalista ${ }^{2}$ e seu propósito é abrir a "caixa preta" onde se processam as entradas e saídas em termos de objetivos políticos e resultados de políticas públicas. Os objetivos indicados no modelo são a finalidade estratégica que a política pública deseja alcançar, e devem ser estabelecidos de forma clara pelos atores políticos para que se consiga mensurar os resultados esperados. Os resultados reais são uma função dos objetivos estabelecidos e do arranjo institucional responsável pela implementação da política pública, especialmente no que se refere às suas capacidades técnicas e políticas. Segundo Pires, Gomide e Amaral (2014, p. 197),

o sucesso ou fracasso de políticas de desenvolvimento estão umbilicalmente ligados à operação dos arranjos institucionais que dão sustentação aos processos decisórios, de execução e controle destas. Assim, a depender da forma como tais políticas estão arranjadas, o Estado possuirá mais ou menos capacidade/debilidade para alcançar seus objetivos.

Portanto, o modelo dos arranjos institucionais captura diversos fatores relacionados à formulação de políticas públicas a partir de uma concepção abrangente do papel do Estado e da sua capacidade em implementar suas políticas.

\footnotetext{
${ }^{2}$ As teorias funcionalistas têm sido um influente arcabouço teórico e conceitual para as ciências sociais, especialmente sociologia e antropologia. Entre teóricos notáveis da área estão Durkheim, Evans-Pritchard, Malinowski, Merton, Parsons e Radcliffe-Brown. Conforme coloca Jaccard e Jacoby (2010, p. 299), existem duas grandes abordagens na teoria funcionalista, uma focada no nível societal (como tipificado pelo trabalho de Durkheim) e outra focada no nível individual (como o trabalho de Malinowski), ainda que haja sobreposições entre elas. Para esta teoria, toda a sociedade tem requerimentos funcionais para sua sobrevivência. A análise funcional explora instituições sociais e políticas e segmentos da sociedade em termos das funções que eles prestam para a sobrevivência do sistema e conceitualiza a sociedade enquanto um sistema de partes interdependentes que tendem ao equilíbrio.
} 
De acordo com Heindenkamp, Louth e Taylor (2013), os Estados vêm atuando a partir de três papéis básicos em relação à base industrial de defesa presente em seu território: como compradores, como reguladores e como patrocinadores. Primeiramente, discutiremos sobre o Estado como comprador no contexto da Política de Aquisição e, posteriormente, analisaremos seu papel enquanto regulador e patrocinador através da Política Industrial de Defesa.

\section{Políticas de Aquisição e Políticas Industriais de Defesa}

A Política Industrial de Defesa de um país faz parte de um subconjunto mais abrangente de Políticas de Defesa. Uma política industrial de defesa está subordinada a uma política de aquisições de defesa de forma mais estrita do que as Políticas de Defesa. Assim, um país pode ter políticas de defesa e políticas de aquisição sem necessariamente perseguir uma política industrial de defesa, conforme se verifica na figura abaixo.

Figura 2 - Relação entre Política de Defesa, Política de Aquisição e Política Industrial de Defesa

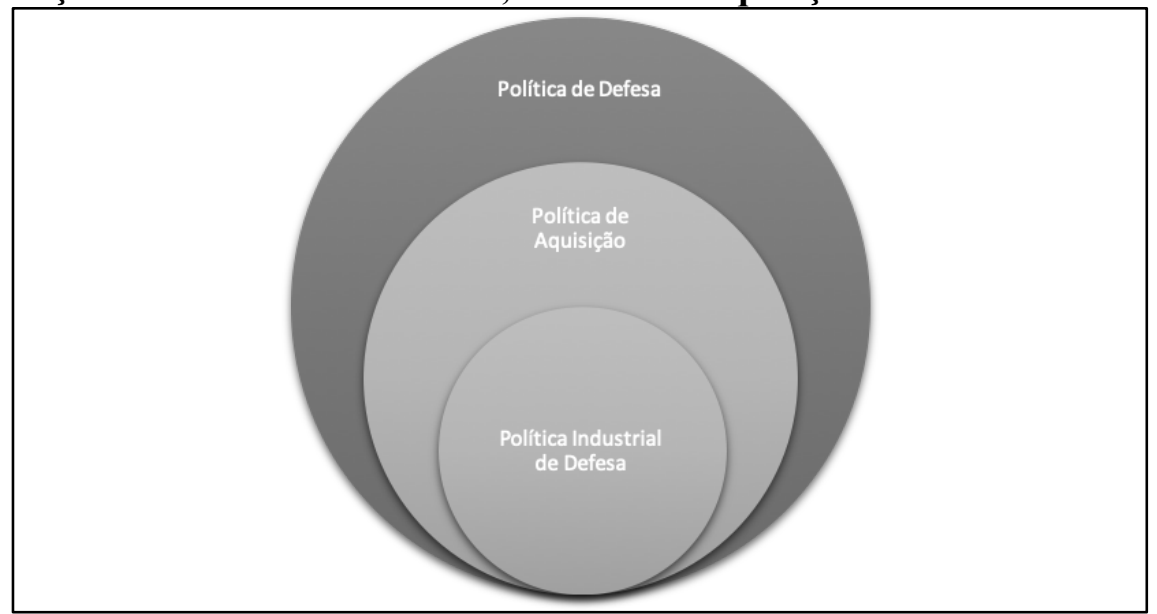

Fonte: Figura elaborada pelo autor.

O conceito simples de Obtenção (procurement) trata dos processos pelos quais uma entidade econômica, seja uma companhia privada ou órgãos governamentais, adquire bens, serviços ou ativos necessários para cumprir suas atividades. Já a Aquisição (acquisition) é um conceito mais complexo e abrange considerações quanto ao Custo do Ciclo de Vida (Life-Cycle Costs), envolvendo a pesquisa, desenvolvimento, produção, manutenção, melhorias e destinação final. Segundo Bohn (2014, p. 1314), o termo aquisição é mais apropriado para lidar com a complexidade do tema por três razões principais:

primeiramente por fornecer um retrato mais real dos custos envolvidos na transação em médio e longo prazos (lembrando que determinados sistemas chegam a demorar décadas para serem desenvolvidos e a manterem-se em operação por outras mais); em segundo lugar, por, a partir deste retrato, permitir uma comparação mais justa entre diferentes sistemas concorrentes, e por último, por facilitar o entendimento de todos possíveis desdobramentos logísticos derivados de uma compra de materiais de defesa e de seus reflexos na sociedade como um todo. 
A Política de Aquisição tem como objetivo principal o fornecimento de poder combatente às Forças Armadas, no intuito de garantir que elas cumpram sua missão constitucional. Afinal, conforme coloca Silva (2015, p. 56), "a finalidade precípua das aquisições militares de um país não é a geração de empregos, nem de exportações de produtos de alto valor agregado ou de transbordamentos tecnológicos para o segmento civil". Entretanto, para abastecer as Forças Armadas com os equipamentos necessários, as Políticas de Aquisição podem ter duas abordagens gerais: garantir de forma segura e confiável o fornecimento de produtos de defesa para manter as capacidades de defesa no estado operacional de prontidão requerido; ou adquirir o que é necessário dentro da lógica de custo-benefício (value-for-money), que não necessariamente significa a compra de menor custo, buscando otimizar as demandas das Forças Armadas em termos de qualidade e planejamento temporal. Conforme coloca Hall, Markowski e Wylie (2010, p. 162), "estes dois objetivos não são necessariamente compatíveis e trade-offs em termos de políticas públicas são inevitáveis". Geralmente, para atingir o primeiro objetivo, os Estados buscam fortalecer sua própria base industrial de defesa, independentemente dos custos. Para o segundo objetivo, os fornecedores podem ser estrangeiros ou nacionais, desde que sejam competitivos internacionalmente em termos de custo.

De forma geral, as políticas de aquisição devem guiar as organizações nacionais de defesa para determinar como compor novas capacidades ou manter operacionalmente as atuais. Nesse sentido, a política de aquisição indica: i) quais são os materiais requeridos que deveriam necessariamente ser fabricados internamente e quais seriam melhor ofertados de fornecedores locais ou estrangeiros que oferecessem o melhor custo benefício (requerimentos de conteúdo local); ii) quais materiais que poderiam ser adquiridos nacionalmente deveriam ser produzidos em fábricas e estaleiros militares ou por fornecedores civis (considerações de fazer ou comprar - make-or-buy); iii) como proceder no que se refere à escolha dos fornecedores, por exemplo, se confiando na competição de mercado ou designando fornecedores preferenciais, ou ainda como solicitar as ofertas dos fornecedores e expressões de interesse (requerimentos de seleção de fornecedores); iv) que tipo de contrato deveria ser utilizado uma vez escolhido o fornecedor (arranjos contratuais); e v) como gerenciar o processo de entrega e o relacionamento com o fornecedor durante toda a duração do ciclo de aquisição e de vida do produto (gerenciamento das relações com fornecedores) ${ }^{3}$.

Conforme colocam Hall, Markowski e Wylie (2010, p. 68-71), os dois primeiros pontos, relacionados com conteúdo local e fazer-ou-comprar (make-or-buy) são questões eminentemente políticas e estratégicas que devem ser determinadas pelas altas esferas de decisão do governo, dado que elas determinam as fronteiras organizacionais e operacionais da Defesa e a estrutura e conduta da indústria de defesa nacional. Os outros aspectos também influenciam o nível estratégico de decisão, como os requerimentos da seleção de fornecedores e os arranjos contratuais, mas esses princípios básicos geralmente são derivados das políticas públicas de aquisição do governo como um todo.

Uma vez que as duas dimensões estritamente estratégicas (conteúdo local e decisão de fazerou-comprar) do processo de aquisição são decididas pelos principais decision makers, o órgão de defesa responsável pela formulação da política de aquisição pode delegar as tarefas dos outros aspectos a níveis mais operacionais da organização. Dessa forma, conforme aponta Silva (2015, p. 56),

\footnotetext{
${ }^{3}$ Para mais detalhes sobre temas abarcados pelas Políticas de Aquisição, ver Sandler e Hartley (1995, p. 117-119).
} 
entre a inviável completa autonomia militar em produtos de defesa, mesmo para as grandes potências, e a ameaça apresentada pelos laços de dependência tecnológica perante fornecedores externos, o que se pode observar [...] são tentativas de traçar um equilíbrio dinâmico entre aquisições no exterior, parcerias internacionais de desenvolvimento (pooling \& sharing) e investimentos domésticos em produtos e componentes considerados estratégicos, a fim de os países assegurarem níveis de superioridade tecnológico-militar e de liberdade de ação, assim como a competitividade de sua base industrial de defesa.

Em algumas políticas de aquisições, determinadas decisões podem ser tomadas caso por caso, como a forma de selecionar os fornecedores e o tipo de contrato a ser utilizado. Entretanto, muitas vezes estas decisões estão constrangidas por políticas governamentais mais amplas, como as políticas do setor público para licitações e contratos administrativos ${ }^{4}$ e as condições de competição do mercado, ou como leis que pró́bem práticas não competitivas de mercado.

Para isso, os países buscam constituir sistemas de aquisições militares, procurando gerir todo o processo da aquisição de variados produtos de defesa, tanto bens quanto serviços ${ }^{5}$. Conforme Hall, Markowski e Wylie (2010, p. 72-73), a organização de aquisição varia de país a país, dependendo i) da natureza do material que costuma ser adquirido (ex. produtos militares ou comerciais de prateleira (MOTS/COTS) ou produtos customizados); ii) da fonte das aquisições (ex. fornecedores globais, empresas locais, fábricas e estaleiros governamentais); iii) de como os materiais são adquiridos (ex. através de editais públicos ou arranjos direcionados); iv) da importância e maturidade da indústria local como fornecedora para as Forças Armadas; v) do caminho das mudanças tecnológicas; e vi) do escopo das funções da aquisição (ex. a extensão em que as aquisições de defesa são utilizadas pelo governo para atingir objetivos econômicos mais amplos).

Assim, os sistemas de aquisição militar podem se configurar de maneira centralizada em um único órgão ou serem descentralizados através dos Serviços das Forças Armadas; serem civis ou militares; serem voltados somente para aquisições de grandes sistemas de armas ou para qualquer compra, seja militar ou administrativa. Nesse sentido, Silva $(2015$, p. 58) coloca que

Para a estruturação de um sistema de aquisições de defesa não há uma "receita" única ou de eficácia comprovada internacionalmente. Cada país, conforme suas peculiaridades históricas, políticas, institucionais, econômicas, culturais, etc., iniciaram suas próprias estruturas e/ou adaptaram modelos já existentes para sua realidade originando, por exemplo, desde o relativamente enxuto, civil e centralizado Swedish Defence Material Administration (FMV) até o robusto, militarizado e centralizado Direction générale de l'ármament (DGA), bem como o modelo altamente complexo e descentralizado adotado pelo Departamento de Defesa dos EUA.

\footnotetext{
${ }^{4}$ No caso brasileiro, parte dos desafios que os Termos de Licitação Especial para a defesa, possibilitados pela Lei n. 12.598 de 2012, procuram resolver são impostos pelos constrangimentos da Lei n. 8.666 de 1993, que dita as regras gerais de licitação e contratação no serviço público brasileiro.

${ }^{5}$ Para um estudo sobre a comparação entre sistemas de aquisição de defesa, ver Behera e Kaushal (2013).
} 
Entretanto, Hall, Markowski e Wylie (2010) apontam que, nas últimas décadas, há uma tendência entre os países, baseados em contribuições de Teorias de Desenho Organizacional ${ }^{6}$, de centralizar suas atividades de aquisição em um único órgão especializado localizado dentro da instituição nacional responsável pela Política de Defesa. Esses órgãos funcionam como um intermediador entre os consumidores, ou seja, as Forças Armadas, e os fornecedores das capacidades militares, a indústria. Assim, ficam responsáveis pela coordenação nas aquisições de grandes valores e compram em grandes quantidades pequenos itens e serviços de suporte que servem a todas as Forças Armadas ${ }^{7}$. Havendo um só órgão, medidas de contabilidade, supervisão e transparência são mais facilmente executáveis. Os autores (Ibidem, p. 72-75) demonstram que os principais argumentos para a centralização, especialmente no caso de países intermediários, incluem

i) economias de escala e escopo derivadas da consolidação da função de aquisição (ex. a partilha dos custos gerais e a eliminação da duplicação de funções);

ii) economia de escopo derivada da consolidação de aquisição de capital (investimentos em novas capacidades) e no suporte do ciclo de vida (apoio logístico para as capacidades) dentro de uma única estrutura organizacional;

iii) aumento da alavancagem de mercado associada a compras maiores;

iv) descontos oferecidos por compras em larga escala de itens administrativos;

v) a crescente complexidade tecnológica dos sistemas de armas, direcionando para a consolidação de expertises técnicas e de gerenciamento de projetos escassas dentro da organização militar;

vi) sistemas de armas intensivos em conhecimento e baseadas em rede que requerem adaptações no ciclo de vida e modificações se beneficiam de uma configuração gerencial altamente centralizada;

vii) economias em rede advindas da estandardização da interoperabilidade de sistemas de armas e eliminação de incompatibilidades tecnológicas (tradução nossa).

A questão relacionada ao sistema de aquisição militar que mais se alinha aos objetivos estratégicos do país é de difícil resolução, não só por sua natureza técnica complexa, mas também por outros desafios que fogem dessa dimensão. Os agentes formuladores e implementadores da Política de Aquisição, independente do sistema de aquisição militar adotado, algumas vezes são constrangidos por fatores estruturais e conjunturais que não estão sob o controle do sistema. Silva (2015, p. 55) aponta que

\footnotetext{
${ }^{6}$ Conforme apontam Hall, Markowski e Wylie (2010, p. 71), as teorias de desenho organizacional sugerem que a especialização nas aquisições a partir da centralização pode aumentar a eficiência de diversas maneiras, entre elas a aglomeração das atividades de compra em agrupamentos de atividades sinérgicas e coesas para aumentar economias de escala e escopo; e a retenção de know-how específico de aquisições a longo prazo para facilitar o contínuo aprimoramento em novas aquisições. Em termos específicos, os autores sugerem que as atividades de aquisição devem ser agrupadas na organização em especialidades: i) pesquisa e inteligência focada em aquisições; ii) aquisição de itens de capital de grande e pequeno valor; iii) suporte operacional e suporte no ciclo de vida de sistemas existentes, incluindo a provisão de peças, compra de consumíveis e fornecimento de serviços; e iv) apoio gerencial e administrativo.

${ }^{7} \mathrm{Em}$ muitos casos, outras organizações dentro do sistema militar nacional podem adquirir pequenos itens diretamente, mas geralmente seguindo as diretrizes gerais de aquisição estabelecidas pelo órgão responsável e sujeitas à verificação de que se buscou a melhor forma de seleção e contratação.
} 
Determinadas aquisições podem compreender inclusive diversos processos e partes interessadas (stakeholders), como interesses de curto prazo de políticos e lideranças burocráticas; pressões dos altos comandos militares por determinados equipamentos (ex. navios aeródromos); questões tecnológico-industriais oriundas de empresários associados ao setor de defesa e de segurança (ex. offsets); perspectivas de geração e manutenção de empregos via projetos militares por parte de agentes políticos; frequentes limitações orçamentárias postas por negociações interburocráticas (ex. cortes e contingenciamentos); vicissitudes diplomáticas em função de certas rivalidades históricas ou regionais; controle de acesso a determinadas tecnologias por meio de regimes, tratados e pressões internacionais; parcerias estratégicas entre países e seus reflexos em termos de exportações de produtos de defesa (ex. desenvolvimento da aeronave KC-390 no Brasil), entre outros processos e atores.

Portanto, dada a complexidade de fatores envolvidos, as aquisições militares continuam sendo um desafio até mesmo para países desenvolvidos. Considerando o envolvimento de diversos atores e processos na aquisição, "para coordená-los e atingir os resultados esperados não há um modelo consolidado na literatura internacional ou na prática: observa-se que cada país busca continuamente aperfeiçoar seus respectivos processos e mecanismos de coordenação, lidando com suas difículdades" (SILVA, 2015). É diante destes cenários e desafios da política de aquisição e no intuito de complementá-la que os países buscam estabelecer políticas industriais de defesa. Essas políticas estão presentes na maior parte dos países que possuem certa capacidade industrial voltada para a defesa, ainda que elas possam não estar formalizadas enquanto tal. Na próxima seção, iremos explorar como a política industrial de defesa é formulada para atingir determinados fins estratégicos.

\section{Política Industrial de Defesa}

A política industrial de defesa, segundo Hall, Markowski e Wylie (2010), complementa as políticas de aquisição no sentido de que é desenhada para encorajar ou direcionar investimentos nas capacidades industriais domésticas necessárias se as aquisições forem demandar fornecimento local. Um país pode perseguir uma política estatal que julgue necessário que a indústria local seja capacitada a produzir os materiais de defesa, seja para manter a soberania operacional de suas forças armadas, seja por razões econômicas mais abrangentes. Portanto, políticas industriais de defesa estão prioritariamente voltadas para o estabelecimento e manutenção de fornecimento nacional e opções de suporte para as Forças Armadas.

As Políticas Industriais de Defesa tornam-se relevantes se existe uma decisão em nível estratégico de confiar em maior ou menor extensão, no momento atual ou no futuro, nos fornecedores nacionais para fabricar ou apoiar as capacidades domésticas de defesa. O grande objetivo de uma política industrial de defesa é assegurar a disponibilidade, confiabilidade e custo-benefício das fontes nacionais de fornecimento de materiais de defesa. Entretanto, segundo Hall, Markowski e Wylie (2010), esses objetivos podem ser conflituosos entre si, uma vez que a disponibilidade de fornecedores nacionais pode depender de grandes investimentos em novas fábricas e habilidades, desviando recursos nacionais de outras áreas. A pequena escala produtiva de alguns países pode ser muito custosa e a disponibilidade de negócios relacionados à defesa dependerá de altas barreiras para importação de produtos de defesa estrangeiros. Estas questões impactam no custo-benefício da 
produção local. Por outro lado, depender de importações impacta na confiabilidade das fontes de fornecimento em tempos de crise e conflagração.

Funcionalmente, uma política industrial de defesa estabelece as diretrizes sobre como i) estabelecer, manter e proteger as capacidades domésticas industriais requeridas; ii) assegurar cadeias de suprimentos suficientemente confiáveis para as capacidades industriais requeridas; iii) manter a viabilidade e prontidão dos fornecedores nacionais preferenciais para atingir os requerimentos das demandas militares - e desenvolver arranjos de salva-guarda se existir perigo de falência do fornecedor; e iv) gerenciar os custos relacionados com as políticas de conteúdo local.

Além da garantia de manutenção da capacidade industrial operacional para produção de materiais de defesa em um país, uma política industrial de defesa muitas vezes também é utilizada para atingir fins econômicos mais amplos, como emprego, inovação e balança de pagamentos. Em relação à utilização de políticas industriais de defesa como estratégia de desenvolvimento econômico por parte dos governos, há diversos argumentos prós e contras, especialmente no que se refere aos processos de spin-off de tecnologias militares para os mercados civis, ao spillover de conhecimento de técnicos e cientistas ligados à inovação militar, e aos impactos diretos da indústria de defesa no PIB e nas exportações.

Uma vez que se decide desenvolver uma política industrial de defesa, ou seja, se decide politicamente arcar com os custos de não buscar necessariamente as opções de preços mais competitivos no mercado internacional em prol de garantir determinada participação da indústria nacional, as estratégias de aquisição variam em quatro possibilidades básicas (Hall, Markowski e Wylie, 2010, p. 176-180): i) substituição de importações com margens de preferência doméstica, onde se admite que empresas locais garantam que seus produtos sejam adquiridos mesmo que estejam acima do preço internacional até determinado percentual; ii) substituição de importações com políticas de conteúdo local, em que se exige que a empresa estrangeira fornecedora produza certa fração do valor do contrato em território nacional ou subcontrate empresas nacionais; iii) substituição de importações com compensações (offset), em que certa porção do valor contratado exige contrapartidas do país da empresa estrangeira, seja a partir de transferência de tecnologia, acordos comerciais, etc.; e iv) acordos de divisão de trabalho em aquisições de multinacionais, em que se busca explorar vantagens competitivas entre os países parceiros ou exigir demandas altas para se atingir economia de escala.

Segundo Berkok, Penney e Skogstad (2012), existem três lógicas principais entre os países para desenhar sua política industrial de defesa, quais sejam:

i) por um lado, a lógica de substituição de importações busca desenvolver a indústria doméstica para diminuir a dependência estratégica e econômica por produtos de defesa de países estrangeiros. A ferramenta mais eficiente para isso seriam as próprias políticas de aquisições das Forças Armadas, que serviriam como instrumentos promotores por demanda. Os governos podem adquirir equipamentos militares diretamente da indústria nacional, ou utilizar-se de acordos de offset para exigirem co-produção doméstica ou produção nacional licenciada. Além disso, uma robusta coordenação entre o governo e a indústria nacional facilitaria a substituição de importações, na medida em que as empresas consigam fazer ajustes e adaptações de longo-prazo para lidar com as necessidades das Forças Armadas Nacionais;

ii) por outro lado, a lógica de desenvolvimento da capacidade exportadora busca capacitar a indústria nacional a inserir-se nas cadeias de valor global, sendo que seu núcleo está em políticas 
de promoção da oferta. Essas políticas são desenhadas para permitir que as empresas nacionais consigam inserir-se mais facilmente no mercado global, dando a elas vantagens competitivas em disputas por contratos de Forças Armadas estrangeiras. Entre os principais instrumentos estão a disseminação de informações, coordenação, desenvolvimento e retenção de talentos, apoio às pequenas e médias empresas, e, não raro, suporte direto (subsídios, lobby político, barganhas diplomáticas) do governo para promover sua indústria de defesa em outros países;

iii) finalmente, aponta-se que é possível uma combinação de ambas as lógicas.

Dentro dessas duas abordagens, Berkok, Penney e Skogstad (2012) identificaram seis grandes dimensões de políticas públicas que os governos utilizam para atingir suas metas: 1. Dimensão de coordenação entre governo e a Indústria de Defesa; 2. Dimensão de promoção e apoio à Pesquisa e Desenvolvimento (P\&D); 3. Dimensão de apoio às Pequenas e Médias empresas (PMEs); 4. Dimensão de Suporte à inserção na cadeia global e valor $(\mathrm{CGV})^{8} ; 5$. Dimensão de criação de ambientes de promoção da competitividade; e 6. Dimensão de $O f f s e t^{9}$.

\section{Dimensão de Coordenação entre Governo e Indústria de Defesa}

Em relação às políticas de coordenação entre governo e indústria de defesa, é importante apontar as dificuldades que o governo pode encontrar para adquirir equipamentos dentro dos prazos requisitados se não existirem empresas nacionais prontas para satisfazer tal demanda. Às empresas, por outro lado, é um desafio manter empregados e capital de maneira eficiente em um mercado no qual a demanda por equipamentos militares não costuma ser constante, mas sim esporádica e instável. Segundo Berkok, Penney e Skogstad (2012, p. 55), políticas que aumentem a coordenação entre o governo e a indústria podem aliviar essas pressões e assegurar um setor industrial de defesa mais estável. Essas políticas podem auxiliar na abordagem da substituição de importações, uma vez que pode ser mais atraente comprar da indústria nacional, já que as empresas nacionais podem estar melhor preparadas para satisfazer a demanda das Forças Armadas. Além disso, esse tipo de política auxilia a criar uma base de informações sobre a própria indústria nacional, de forma que os formuladores de políticas de aquisição e gerentes de projetos estratégicos podem direcionar de maneira mais efetiva as demandas para as empresas nacionais.

\footnotetext{
${ }^{8}$ Conforme afirma Oliveira (2015, p. 38), “o comércio internacional vem crescendo em média 5,4\% anualmente durante os últimos vinte anos, ao mesmo tempo em que passa por profundas transformações em decorrência das novas formas de organização e coordenação da produção industrial. A cadeia produtiva de bens, que anteriormente concentrava-se dentro de um determinado país e na maioria das vezes nas mãos de uma única empresa, hoje se encontra dispersa geograficamente e fragmentada em diversas etapas, nas chamadas "cadeias globais de valor (CGV)"”". A internacionalização das cadeias de valor também influenciou a estrutura das indústrias de defesa. Segundo Dunne (2009, p. 27), “além das compras entre países de produtos finais, as companhias também estão mudando suas cadeias de fornecimento, como é o exemplo das compras da BAE System na África do Sul. O aumento dos acordos de offset encorajarou este desenvolvimento e deu aos países importadores a oportunidade de consolidar mercados de nicho ao fazer parte da cadeia de suprimentos dos grandes produtores internacionais". O autor também coloca que os governos estão reconhecendo cada vez mais os altos custos do P\&D para tecnologias avançadas de defesa e que a viabilidade de produção de pequenos países passa por economias de escala que só são possíveis através da colaboração internacional e arranjos industriais cooperativos (Dunne, 2009, p. 27). ${ }^{9}$ Quando os países decidem por fazer uma compra para suas Forças Armadas de algum fornecedor estrangeiro, é relativamente usual que se exija algum tipo de compensação, também chamada de offset. Conforme a Portaria Normativa n. 764/ MD/2002 dispõe, offset é "toda e qualquer prática compensatória acordada entre as partes, como condição para a importação de bens, serviços e tecnologia, com a intenção de gerar benefícios de natureza industrial, tecnológica e comercial" (BRASIL, 2002, p. 12). Dessa forma, o fator determinante da possibilidade de offset (compensação) é o poder de compra do país importador.
} 
Como exemplo, os autores mencionam que a coordenação entre o governo de Israel e sua Indústria de Defesa se dá muito a partir dos sistemas de Pesquisa e Desenvolvimento de maneira permanente, ou seja, independente de haver um grande projeto âncora. A Coréia do Sul, por sua vez, estabeleceu um sistema de "Equipe Integrada de Projetos" (Integrated Project Team), composta por civis e militares, destinado a supervisionar e coordenar as iniciativas de aquisição e prover sugestões de aprimoramento ao planejamento, orçamento e confiabilidade do projeto. Já o Reino Unido possui um programa de pré-qualificação de algumas empresas para licitações futuras, preparando-as para lidar com suas demandas.

\section{Dimensão de Promoção e Apoio a P\&D}

As Políticas de promoção e apoio a P\&D geralmente se justificam na percepção de que muitos avanços tecnológicos resultam do investimento na indústria de defesa e de que haveria transbordamentos para outros setores da economia. Mais do que isso, segundo Berkok, Penney e Skogstad (2012, p. 57), um país que investe de forma sistemática em empresas que desenvolvem novas tecnologias espera penetrar no mercado global e posicionar sua indústria na cadeia global de fornecimento. Existe uma crescente demanda por bens de alta tecnologia, e um país que atinge determinadas fronteiras tecnológicas pode sustentar um forte setor exportador. Além disso, se as empresas nacionais não possuem o know-how tecnológico e industrial para desenvolver e produzir armamentos avançados, o governo precisará importar de outros países. Assim, investimentos em P\&D respondem tanto à abordagem da substituição de importações quanto da promoção de exportações.

A política de apoio a P\&D na Coréia do Sul aposta muito nos acordos de coprodução em defesa no intuito de garantir a transferência de tecnologia, buscando desenvolver capacidades produtivas domésticas em áreas que não possui vantagens comparativas. Já a Austrália provê financiamento subsidiado a propostas inovadoras e de alto risco de Pequenas e Médias empresas que contenham alto grau tecnológico e que estejam alinhadas ao Programa de Prioridades de Capacitação Industrial.

\section{Dimensão de Apoio às Pequenas e Médias Empresas (PMEs)}

As políticas de apoio às pequenas e médias empresas (PMEs) começam a ser desenvolvidas a partir do diagnóstico de uma questão já debatida nesta tese: a consolidação da indústria global de defesa em poucos prime contractors multinacionais e as restrições de entrada ao mercado internacional. Considerando que é muito difícil para empresas deste porte serem notadas por grandes integradores, dificultando assim sua entrada na cadeia global de suprimentos, políticas que promovam assistência às PMEs podem auxiliá-las a se tornar exportadoras. Conforme aponta Berkok, Penney e Skogstad (2012, p. 58), ao se tornarem mais eficientes e garantirem maior sustentabilidade, elas podem tanto fornecer para as Forças Armadas nacionais quanto garantirem espaço na cadeia global a partir de parcerias estratégicas, seja com prime contractors, seja com PMEs estrangeiras. Além disso, o incentivo às PMEs está relacionado com o imperativo estratégico da capacidade de mobilização do tecido econômico e social de um país em situações de emergência nacional, dada a maior capilaridade que as PMEs têm na sociedade em comparação com grandes empresas.

A Austrália desenvolveu o Programa de Demonstração de Capacidades e Tecnologias (Capability and Technology Demonstrator Program) que possibilita que PMEs exibam suas potencialidades às grandes empresas nacionais e internacionais e contatem governos estrangeiros. $\mathrm{Na}$ Coréia do Sul, há vários incentivos para que PMEs entrem no mercado de defesa, desde que, como 
contrapartida, tenham por objetivo de longo prazo serem competitivas internacionalmente. Já em Israel, a maior parte da sua base industrial de defesa é composta por empresas relativamente grandes e o setor de defesa conta com poucos novos entrantes. Em geral, quando há algum tipo de apoio específico às PMEs, se dá através de subsídios para P\&D.

\section{4. $\quad$ Dimensão de Suporte à inserção na cadeia global de valor (CGV)}

As políticas de suporte à inserção na CGV compreendem as iniciativas às PMEs, e também os incentivos às grandes empresas, pois a venda diretamente a outros países geralmente é feita em negociação de governo a governo (gov-to-gov). Assim, essas políticas geralmente lidam com a regulação das exportações de produtos de defesa, com iniciativas de marketing dos produtos nacionais, com facilitação de negociação com governos estrangeiros e empresas multinacionais e com linhas especiais de crédito para a exportação.

Aproximadamente $70 \%$ de todos os sistemas de armas produzidos em Israel são exportados, e isso se faz possível, em partes, graças ao forte apoio governamental no marketing internacional dos produtos de defesa israelenses, às missões internacionais lideradas pelo governo e à pró-atividade das embaixadas israelenses em mercados de defesa prósperos. Já o governo do Reino Unido age mais no momento anterior ao ato da exportação. Ao definir as tecnologias específicas que pretendem produzir domesticamente, os ingleses criam fundos de pesquisa específicos que possibilitam a criação de produtos tecnologicamente avançados. A partir da compra dos produtos ingleses por suas Forças Armadas, o governo inglês implicitamente afirma a qualidade dos produtos, facilitando de maneira significativa as suas exportações.

\section{Dimensão para Criação de Ambientes de Promoção da Competitividade}

Uma etapa importante para a sustentação de uma base industrial de defesa nacional é o estabelecimento de um ambiente em que as empresas desejem investir. Para isso, é necessário atentar a quatro fatores: i) desenvolvimento de mão de obra técnica e especializada; ii) regulamentações claras de acesso ao mercado (normatizações e certificações); iii) regime tributário competitivo; e iv) linhas de financiamento adequadas ao setor de defesa.

A indústria de defesa é geralmente muito técnica, requerendo uma força de trabalho altamente especializada. Assim, são necessários investimentos públicos para o desenvolvimento de escolas técnicas, cursos profissionalizantes e cursos superiores voltados para a área de defesa. Segundo Berkok, Penney e Skogstad (2012, p. 59), as barreiras de entrada no mercado de defesa precisam ser diminuídas, pois lidar com regulações extensas e obscuras podem afastar empreendedores. Além disso, arquiteturas fiscais que possibilitem as empresas de defesa a serem mais competitivas no mercado internacional e linhas de financiamento que compreendam a lógica especial do setor de defesa também são importantes para o estabelecimento de um ambiente próspero de investimentos privados na área.

A Austrália possui um projeto especial de capacitação de mão de obra nas áreas que pretendem manter a capacitação industrial e tecnológica para estimular um ambiente competitivo. Chamado "Capacitando a Indústria de Defesa da Austrália” (Skilling Australia's Defence Industry), este programa oferece bolsas de estudo buscando três objetivos: aprimorar os trabalhadores já empregados na Indústria de Defesa; aumentar a quantidade e qualidade de trabalhadores voltados para áreas prioritárias em defesa; prover fundos para que as próprias empresas de defesa ofereçam atividades de 
treinamento em áreas onde se identifique falta de recursos humanos com capacidades técnicas, comerciais ou de gestão. Já a abordagem política israelense para promover um ambiente competitivo para o investimento, especialmente o estrangeiro, no país, consiste em permitir que investidores estrangeiros comprem até $49 \%$ de empresas nacionais, com incentivos especialmente no que se refere ao abatimento do valor investido nas exigências de contrapartida.

\section{Dimensão de Offset}

As políticas de offset vêm sendo amplamente utilizadas por diversos países. Enquanto alguns usam offsets para a criação de empregos ou compensações comerciais para equilíbrio da balança de pagamentos, a maior parte dos países vê neste instrumento oportunidades de transferência de tecnologia. Alguns governos vêm exigindo offsets para todos os contratos acima de determinado valor, geralmente como uma fração do valor do contrato de aquisição.

A política sul-coreana de offset estabelece que 50\% do valor total do contrato deve estar sujeito a compensações, sendo que $60 \%$ dessas compensações devem ser de natureza tecnológica e industrial como coprodução, transferência de tecnologia, investimentos em P\&D e desenvolvimento técnico. Já a política da Suécia é mais restrita, exigindo $100 \%$ do valor do contrato em compensações tecnológicas, principalmente elementos de coprodução, sendo que offsets indiretos como investimentos na indústria doméstica ou contrapartidas comerciais são inelegíveis.

Na próxima seção, iremos sistematizar os conceitos trabalhados até o momento em conjunto com as políticas públicas apontadas para desenhar um modelo analítico útil para a análise de políticas industriais de defesa.

\section{Modelo Analítico para Políticas Industriais de Defesa}

O objetivo deste artigo é propor um modelo analítico para políticas públicas do setor de defesa, em específico as políticas industriais de defesa, baseado em arranjos institucionais. Nesse modelo, a realização da finalidade estratégica de se criar uma base industrial de defesa nacional passa por os arranjos institucionais arquitetados pelo Estado, e resulta em uma configuração específica do modelo de desenvolvimento, consolidação e sustentabilidade da Base Industrial de Defesa. Estamos cientes que uma série de outros fatores influencia a variável dependente em questão ${ }^{10}$, mas consideramos que esta limitação não impede uma análise consistente da relação entre os conceitos utilizados.

Em relação à perspectiva teórica, afirmamos que o desenvolvimento da Base Industrial de Defesa é uma estratégia possível e viável para a endogeneização dos Centros de Decisão ${ }^{11}$, em especial para o domínio da digitalização enquanto coluna vertebral do desenvolvimento econômico e

\footnotetext{
${ }^{10}$ Desde aspectos macropolíticos e macroeconômicos do país, até questões relativas ao tecido industrial instalado, à infraestrutura educacional e à doutrina e organização das Forças Armadas.

${ }^{11}$ Para que um país não fique à margem do desenvolvimento dos paradigmas técnico-econômicos que dominam a dinâmica internacional, é necessário criar mecanismos institucionais que deem conta dos desafios econômicos. É nesse sentido que o conceito de "Centro de Decisão" de Celso Furtado (1962), um dos fundadores da escola cepalina, torna-se fundamental para compreender o processo de endogeneização do desenvolvimento econômico e tecnológico. Essa ideia é compreendida como a capacidade de o Estado gerir, da forma como lhe convier, o seu próprio desenvolvimento econômico a partir do controle das tecnologias e técnicas produtivas nucleadoras de determinada etapa do desenvolvimento econômico. Ou seja, relaciona-se com os mecanismos político-institucionais e sociais criados para consolidar a capacidade de um país em tomar decisões relativas ao seu próprio desenvolvimento em um novo paradigma técnico-econômico.
} 
tecnológico no século XXI ${ }^{12}$. Dado que a defesa é um bem público que o Estado tem como função fundamental prover e, portanto, encontra legitimidade suficiente para agir estrategicamente a partir da promoção de políticas robustas, ela pode ser utilizada como forma de entronizar o Centro de Decisão da digitalização. Os esforços voltados para o desenvolvimento da BID podem abrir caminhos para a internalização de tecnologias críticas e processos produtivos avançados que fazem parte da base de um tecido industrial e tecnológico capaz de modernizar uma economia nacional. Além disso, dado que para desenvolver a BID é necessário um papel ativo do Estado, ela força que haja certa reorganização e fortalecimento das suas instituições. Ou seja, o desenvolvimento da BID demanda que um Estado fortaleça sua capacidade estatal, isto é, seus instrumentos de penetração na sociedade e implementação de políticas públicas. Dessa forma, aqui consideramos secundária a relação entre gastos militares e crescimento econômico. A BID tem um papel fundamentalmente estratégico no desenvolvimento econômico e tecnológico de um país, ao transformar não só os meios produtivos de uma economia, como também a relação entre Estado e Sociedade em uma nação.

Para a BID ser desenvolvida e consolidada, é fundamental que haja uma motivação política que faça com que o processo se inicie, e esta motivação ${ }^{13}$ geralmente se vincula com a forma como o Estado pretende inserir-se internacionalmente. Isto é, a BID é um meio para se atingir determinado fim no âmbito internacional. Nesse sentido, a finalidade estratégica atribuída à BID é uma função das capacidades nacionais frente aos constrangimentos estruturais do ambiente estratégico em que o Estado está inserido, do padrão de relacionamento com seus adversários próximos e da sua inserção histórica no sistema internacional. Além disso, a motivação política para se desenvolver ou consolidar a BID está intimamente relacionada com as capacidades produtivas e tecnológicas já existentes no país, ou seja, depende do seu posicionamento na hierarquia internacional de defesa ${ }^{14}$.

Os países intermediários da hierarquia internacional da indústria de defesa, como o Brasil, ao atribuir a finalidade estratégica à BID, precisam harmonizar os acentuados custos de oportunidade (trade-offs) colocados pelo trilema da modernização de defesa ${ }^{15}$. Os constrangimentos orçamentários

\footnotetext{
${ }^{12}$ Concordamos com Martins (2008, p. 15) quando o autor coloca que "capacidades militares digitais no estado da arte (o que é feito através da aquisição de sistemas, transferências e nacionalização de tecnologia) reestruturam o Estado fisicamente e permitem a recuperação do centro de decisão econômica. A digitalização equivale nos dias de hoje para a estratégia nacional o que, ao seu tempo, foi a aquisição do centro de decisão da siderurgia, da química fina, e da energia nuclear. Em síntese, a recuperação da capacidade operacional das forças armadas importa para todo o desenvolvimento socioeconômico. A digitalização acarreta uma crescente instabilidade do sistema internacional que, ao criar ameaças de guerra local, engendra como resposta sistêmica investimentos militares. Se, ao invés de adquirir material bélico no exterior, optar-se pela produção nativa, estes investimentos podem dotar as potências regionais do centro de decisão (semicondutores e supercondutores) que são o núcleo da economia contemporânea".

${ }^{13}$ Hoyt (1997) identifica quatro abordagens teóricas principais que são utilizadas para analisar as variáveis que motivam os países a desenvolver uma base industrial de defesa própria: a) estrutural/dependência; b) dominação/sistema-mundo; c) econômica/desenvolvimentista; e d) histórico/sistêmica. Entre os principais autores dessas abordagens estão Buzan e Herring (1998) e Krause (1992).

${ }^{14}$ Sobe a hierarquia internacional de defesa, ver Bitzinger (2015).

${ }^{15}$ A inserção de países como o Brasil na hierarquia global da indústria de defesa e, principalmente, a capacidade de renovar os meios materiais de suas Forças Armadas passam, segundo Franko (2014), pelo "Trilema na Modernização da Defesa". A definição deste trilema - inspirado no trilema da macroeconomia onde não se pode escolher mais do que duas alternativas entre política monetária independente, mercado de capitais aberto e taxa de câmbio fixa - aponta que um país não consegue harmonizar, ao mesmo tempo, quando se trata de sua indústria de defesa, a sustentabilidade econômica, a autonomia estratégica para segurança e a inserção na cadeia global de valor. Neste trilema, só é possível optar por dois dos três fatores, ficando-se obrigado a abrir mão de um deles. Ou seja, considerando a necessidade estratégica de reequipar e modernizar as Forças Armadas brasileiras, se o Brasil deseja retomar seu caminho de crescimento econômico estável, precisará escolher entre o seu "compromisso profundamente enraizado de autonomia e uma maior integração na cadeia
} 
e fiscais impõem o desafio a esses países de manter modernizada suas Forças Armadas em um contexto de rápida inovação em tecnologias militares e de custos cada vez mais elevados, considerando que é necessário manter determinado grau de autonomia no fornecimento de armamentos ao passo que a inserção na cadeia global de valor é fundamental para absorver tecnologias avançadas.

Para que esses desafios sejam enfrentados de maneira eficiente, é necessário que o Estado se empenhe ativamente por meio de diferentes políticas públicas, agindo não só através de seu poder de compra e instrumentos regulatórios, mas também como promotor do desenvolvimento da Base Industrial de Defesa. Nesse sentido, não basta que o Estado faça aquisições e garanta um contexto orçamentário estável e em expansão. É preciso que haja uma efetiva concertação entre Política de Defesa, Política Externa e Políticas de Desenvolvimento Econômico, Ciência, Tecnologia e Inovação no intuito de se articular os requisitos da BID que o país necessita, em que condições e a que custo. Ou seja, é preciso criar um modelo de desenvolvimento e sustentabilidade da BID que consiga lidar com os desafios impostos pelo Trilema da Modernização.

O Estado precisa fortalecer sua capacidade estatal para ser capaz de implementar satisfatoriamente as políticas públicas, tanto do lado das políticas de demanda quanto das políticas de oferta em relação ao setor industrial de defesa. Consideramos que arranjos institucionais robustos e a sua eficiência para atingir objetivos demandados pelo Estado são parte do que se constitui enquanto capacidade estatal.

É possível adaptar o modelo analítico dos arranjos institucionais de Gomide e Pires (2014) para a análise de políticas públicas para o desenvolvimento da indústria de defesa. Para avaliarmos políticas de aquisição, trata-se de analisar as duas decisões estratégias principais sobre a função predominante da política: i) garantir o acesso a equipamentos de defesa formando cadeias de suprimento seguras que possam fornecer ou manter capacidades de defesa necessárias no nível operacional requerido; e/ou ii) adquirir o que é necessário de maneira custo-efetiva dentro do prazo e da qualidade requerida pela defesa (Hall, Markowski e Wylie, 2010). Posteriormente, é preciso avaliar as principais diretrizes que permeiam as práticas de aquisição (requerimentos de conteúdo local, decisões de fazer ou comprar, requerimentos da seleção de fornecedores, existência de objetivos econômicos amplos, etc.) e a organização institucional dos mecanismos que executam a política (se o processo de aquisição é centralizado ou descentralizado; prioritariamente civil ou militar; e se as instituições responsáveis são mais ou menos autônomas em relação ao principal órgão decisor, no caso, o Ministério da Defesa).

Geralmente, a existência de uma Política Industrial de Defesa associada à necessidade de desenvolvimento e consolidação de uma BID está relacionada com o objetivo da política de aquisição de garantir a segurança de acesso a equipamentos de defesa. Por sua vez, o objetivo de adquirir equipamentos de defesa de maneira custo-efetiva não necessariamente prevê a existência de uma Política Industrial de Defesa, e, quando há, está mais relacionada com a meta de sustentar as capacidades atuais da BID nacionais, sem o compromisso de desenvolver novas capacidades tecnológicas e industriais.

Em relação à Política Industrial de Defesa, a primeira tarefa é identificar a lógica principal que baseia o objetivo da política. Vale apontar que uma vez que a Política Industrial de Defesa existe, o

global de valor da defesa" (Franko, 2014, p. 2, tradução nossa). 
objetivo é sempre o desenvolvimento, consolidação e sustentabilidade da BID nacional. O que diferencia de um caso para o outro é a lógica dos meios pelos quais tal objetivo será alcançado e os mecanismos desenvolvidos. Conforme já avaliamos, Berkok, Penney e Skogstad (2012) apontam três lógicas principais: i) a lógica da substituição de importações, cujo foco central é desenvolver a indústria doméstica para diminuir a dependência estratégica e econômica por produtos de defesa em relação a países estrangeiros, valendo-se especialmente de acordos de compensação para garantir a participação de sua indústria nacional em acordos de coprodução e para transferir tecnologias críticas; ii) a lógica de desenvolvimento através da promoção de exportações, que busca capacitar a indústria nacional a inserir-se nas cadeias de valor global; iii) e a combinação de ambas as lógicas.

A política industrial de defesa como um conjunto de diversas ações em dimensões distintas. Assim, são bons instrumentos analíticos as seis grandes dimensões de políticas públicas apontadas por Berkok, Penney e Skogstad (2012) que os governos utilizam para atingir suas metas em termos de políticas industriais de defesa: 1. Dimensão de coordenação entre governo e a Indústria de Defesa; 2. Dimensão de promoção e apoio à Pesquisa e Desenvolvimento (P\&D); 3. Dimensão de apoio às Pequenas e Médias empresas (PMEs); 4. Dimensão de Suporte à inserção na cadeia global de valor $(\mathrm{CGV})$; 5. Dimensão de criação de ambientes de promoção da competitividade; 6. Dimensão de Offset. Nesse caso, a análise se retém nos arranjos institucionais que formulam e implementam as ações relacionadas a estas seis grandes áreas de políticas públicas que compõem uma política industrial de defesa.

Ao analisar o arranjo institucional da política de aquisição e da política industrial de defesa compreendido nas seis áreas de políticas públicas mencionadas acima, é necessário verificar, além das burocracias executivas envolvidas, os mecanismos de participação dos atores políticos e sociais atuantes nas políticas de defesa, as instâncias de representação da sociedade civil afetada (como a indústria, sindicatos, etc.) e os instrumentos de controle, sejam burocráticos, parlamentares ou judiciais. Estes fatores são necessários para avaliarmos a capacidade política e a capacidade técnicoadministrativa do arranjo institucional para cumprir seus objetivos.

Ao avaliarmos a capacidade política do arranjo institucional, levamos em conta: i) a existência e formas de interações das burocracias do Executivo com os agentes do sistema políticorepresentativo; ii) a existência e operação efetiva de formas de participação social; e iii) a atuação dos órgãos de controle internos ou externos. Já a capacidade técnico-administrativa, verificamos três critérios: i) a presença de organizações com recursos humanos, financeiros e tecnológicos adequados e disponíveis para a condução de ações; ii) a existência e operação de mecanismos de coordenação (intra e intergovernamentais); e iii) estratégias de monitoramento (produção de informações, acompanhamento e exigência de desempenho). Além disso, Schapiro (2014, p.252) aponta que, quando tratamos de políticas que tendem a ser multisetoriais e a lidar com diversas esferas governamentais, como o caso de políticas industriais, também é importante se levar em conta o grau de centralidade decisória e o grau de responsabilização das autoridades envolvidas na política.

Conforme apontam Gomides e Pires (2014), a capacidade técnico-administrativa está relacionada com o grau de execução dos objetivos propostos pela política. Ou seja, ao avaliar o resultado decorrente da capacidade técnico-administrativa do arranjo institucional da política industrial de defesa, estamos avaliando o output do programa ou da política em si, e não os outcomes ou consequências dela no ambiente em que está inserida. Por sua vez, a capacidade política está relacionada ao grau de inovação da política pública, ou seja, o quanto ela é capaz de se adaptar e se 
reinventar frente a desafios e situações não esperadas quando da sua formulação. Assim, é importante apontar que o grau de execução e o grau de inovação que avaliamos é o resultado relativo à lógica dos meios que a política industrial de defesa se propõe a estabelecer.

Dessa forma, podemos sintetizar nosso modelo analítico conforme a figura abaixo:

Figura 3 - Modelo Analítico do Trabalho

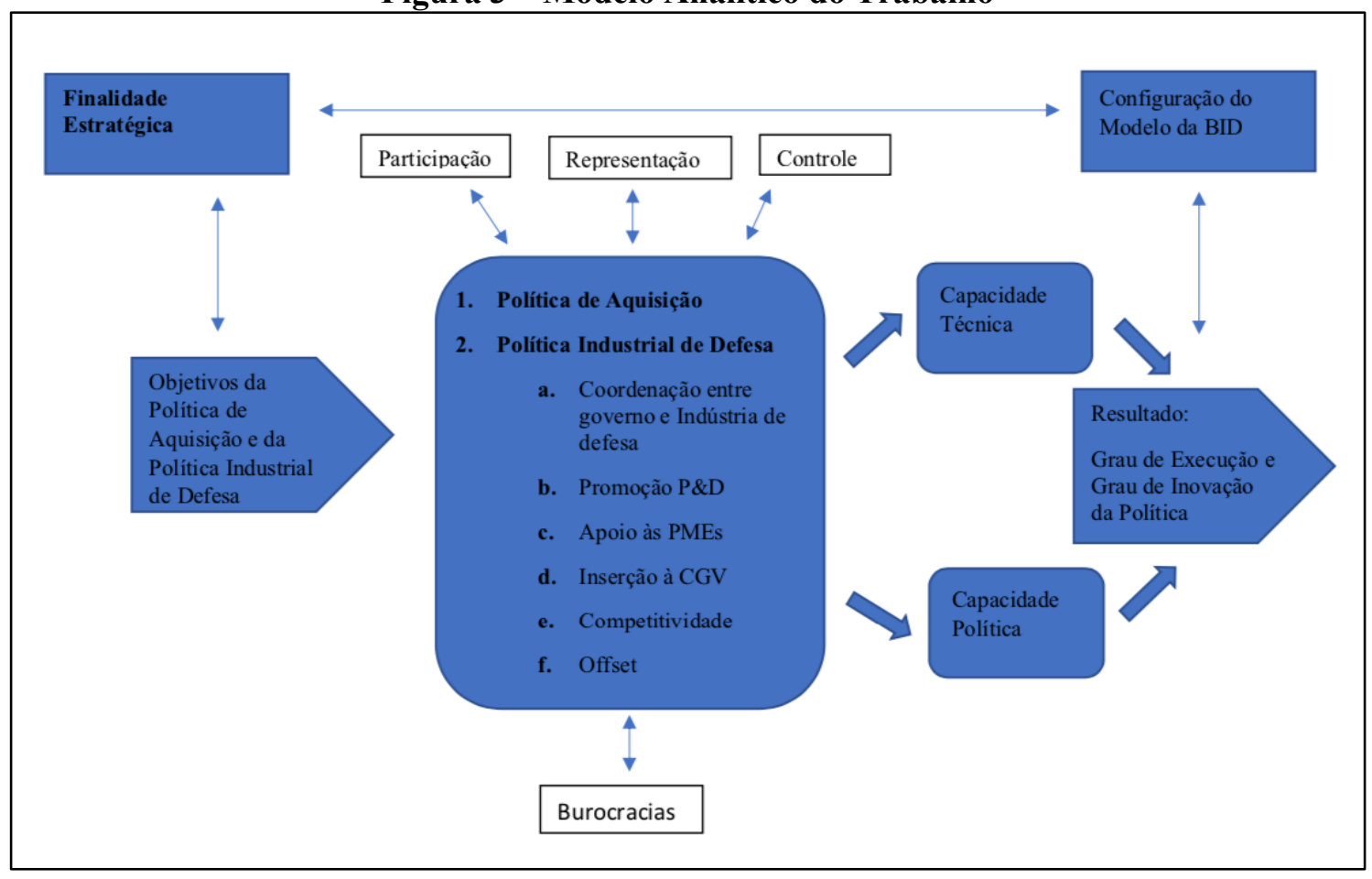

Fonte: Elaborada pelo autor, adaptada de Gomide e Pires (2014).

Por sua vez, as capacidades do arranjo institucional da política de aquisição e da política industrial de defesa auxiliam o país a lidar com o Trilema da Modernização de Defesa de Franko (2013), levando a formas distintas de configuração do Modelo de Desenvolvimento e Sustentabilidade da BID nacional. Este trilema mostra que um país não consegue harmonizar, ao mesmo tempo, quando se trata de sua indústria de defesa, a sustentabilidade econômica, a autonomia estratégica para segurança e a inserção na cadeia global de valor. Só é possível optar por dois dos três fatores, sendo-se obrigado a abrir mão de um deles. Assim, a configuração da Base Industrial de Defesa estaria mais voltada para dois dos três fatores (sustentabilidade econômica, inserção na cadeira global de valor e autonomia estratégica), e isto importa no tipo de investimento público e direcionamento estratégico que o Estado dará para as empresas de defesa e o tipo de desenvolvimento industrial e tecnológico que a base industrial de defesa promoverá.

Este modelo não pretende estabelecer uma relação de causalidade entre as diversas variáveis analisadas, mas sim compreender como elas se relacionam e configuram um modelo desenvolvimento, consolidação e sustentabilidade da base industrial de defesa nacional. Dessa forma, partimos da premissa de que a finalidade estratégica atribuída a BID relaciona-se com os objetivos da política de aquisição e da política industrial de defesa, que por sua vez necessitam de arranjos institucionais capazes de executar suas metas e que influenciam na forma como o país lidará com os constrangimentos advindos da sua posição intermediária na hierarquia global de produtos de defesa. 
Assim, consideramos que a finalidade estratégica e a configuração escolhida para lidar com os desafios impostos pela hierarquia global influenciam no desenho do modelo de desenvolvimento, consolidação e sustentabilidade da BID.

\section{Considerações Finais}

Este artigo teve como objetivo propor um modelo de análise de políticas de aquisição e industriais de defesa por meio da lógica dos arranjos institucionais. A partir da revisão da literatura sobre políticas de aquisição e industriais de defesa, procurou-se articular os principais conceitos ao ferramental analítico oferecido por Gomide e Pires (2014), adaptando o modelo dos arranjos institucionais, com $\mathrm{o}$ intuito de oferecer um instrumental sistemático tanto para acadêmicos quanto para gestores de políticas da área em questão.

O pressuposto teórico do modelo é a potencialidade da indústria de defesa ser um eixo transformador do tecido industrial e tecnológico de um país, além de uma necessidade para a soberania nacional. Sendo assim, parte significativa da discussão e do modelo proposto centra-se em como é possível consolidar uma base industrial de defesa apesar dos desafios impostos pela hierarquia internacional dos produtos de defesa. Nesse sentido, o trilema da modernização de defesa mostra-se útil para compreender os constrangimentos que são necessários mitigar para progredir no processo de desenvolvimento da indústria de defesa nacional.

A aplicação do modelo proposto por esse artigo em estudos de caso é o próximo passo lógico para a validação, refutação ou aperfeiçoamento das variáveis e das correlações analisadas. A agenda de pesquisa da Economia da Defesa e da Política Industrial pode avançar com estudos comparativos entre diferentes casos nacionais utilizando-se de um mesmo arcabouço analítico e conceitual. Além disso, o ferramental proposto pode mostrar-se útil aos formuladores e gestores de políticas públicas focadas na promoção da indústria de defesa.

\section{Referências}

BEHERA, Laxman; KAUSHAL, Vinay. Defence Acquisition: International Best Practices. New Delhi: Pentagon Press, 2013.

BERKOK, Ugurhan; PENNEY, Christopher; SKOGSTAD, Karl. Defence Industrial Policy Approaches and Instruments [Online]. 2012. Disponível em:

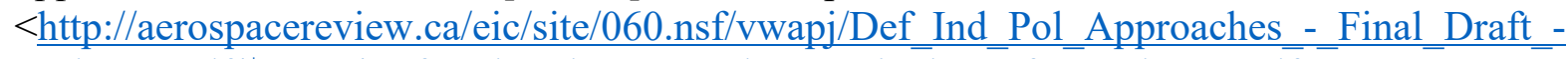
July_13.pdf/\$FILE/Def_Ind_Pol_Approaches__Final_Draft_-_July_13.pdf $>$. Acesso em: 22 fev. 2016.

BITZINGER, Richard. New ways of thinking about the global arms industry: dealing with 'limited autarky' [Online]. Strategic Insights, Australian Strategic Policy Institute, Nov. 2015. Disponível em: $<$ https://www.aspistrategist.org.au/new-ways-of-thinking-about-the-global-arms-industrydealing-with-limited-autarky/>. Acesso em: 30 jan. 2017.

BOHN, Eduardo Cesar. Indústria de Defesa e Processos de Aquisição no Brasil: uma sugestão de debate baseado em modelos para países em desenvolvimento. Porto Alegre: UFRGS, 2014. 
BRASIL. Ministério da Defesa. Portaria Normativa n. 764/MD, de 27 de dezembro de 2002. Aprova a Política e as Diretrizes de Compensação Comercial, Industrial e Tecnológica do Ministério da Defesa. Disponível em:

$<$ https://www.defesa.gov.br/arquivos/File/legislacao/emcfa/publicacoes/port_norm_n0_764_md_20 02 pltc_dtz_comps_cmc_indu_tecnl_md.pdf $>$. Acesso em: 25 nov. 2019.

BUZAN, Barry; HERRING, Eric. The Arms Dynamics in World Politics. Colorado: Lynne Rienner Publishers, 1998.

CHANG, Ha-Joon. The Political Economy of Industrial Policy. London: Macmillan, 1994.

DUNNE, Paul. Developments in the Global Arms Industry from the End of the Cold War to the mid-2000s. In: BITZINGER, Richard (Ed.). The Modern Defense Industry: political, economic and Technological issues. Santa Barbara: Praeger Security International, 2009.

EVANS, Peter; RAUCH, James. Bureaucracy and growth: A cross-national analysis of the effects of 'Weberian' state structures on Economic Growth. American Sociological Review, v. 64, n. 5, p. 748-765, 1999.

FINNEGAN, Philip. The Evolution of International Defense Hierarchies. In: BITZINGER, Richard (Ed.). The Modern Defense Industry: political, economic and Technological issues. Santa Barbara: Praeger Security International, 2009.

FRANKO, Patrice. The Defense Acquisition Trilemma: The Case of Brazil. Strategic Forum, n. 284, p. 1-16, 2014.

FURTADO, Celso. Formação Econômica do Brasil. São Paulo: Companhia das Letras, 1962 [2006].

GOMIDE, Alexandre de Ávila; PIRES, Roberto Rocha (Eds.). Capacidades Estatais e Democracia: Arranjos Institucionais de Políticas Públicas. Brasília: IPEA, 2014.

HALL, Peter; MARKOWSKI, Stefan; WYLIE, Robert. Defence Procurement and Industry Policy: a small country perspective. Nova York: Routledge, 2010.

HAYWARD, Keith. The Globalization of Defense Industry. In: BITZINGER, Richard (Ed.). The Modern Defense Industry: political, economic and Technological issues. Santa Barbara: Praeger Security International, 2009.

HEIDENKAMP, Henrik; LOUTH, John; TAYLOR, Trevor. The Defence Industrial Triptych: Government as Customer, Sponsor and Regulator. London: Whitehall Papers/Royal United Services Institute, 2013.

HOYT, Timothy. Rising Regional Powers: new Perspectives on Indigenous Defence Industries and Military Capability. Washington: The John Hopkins University, 1997.

JACCARD, James; JACOBY, Jacob. Theory Construction and Model-Building Skills: a practical guide for social scientists. New York: The Guilford Press, 2010.

KRAUSE, Keith. Arms and the State: Patterns of Military Production and Trade. Cambridge: Cambridge University Press, 1992.

MARTINS, José M. Q. Digitalização e guerra local: fatores do equilíbrio internacional. Tese de Doutorado, Ciência Política, UFRGS. Porto Alegre, 2008.

OLIVEIRA, Susan Elizabeth Martins Cesar de. Cadeias globais de valor e os novos padrões de comércio internacional: estratégias de inserção de Brasil e Canadá. Brasília: FUNAG, 2015. 
PIRES, Roberto Rocha C.; GOMIDE, Alexandre de Ávila. Análise Comparativa: Arranjos de Implementação e resultados de políticas públicas. In: GOMIDE, Alexandre de Ávila; PIRES, Roberto Rocha (Eds.). Capacidades Estatais e Democracia: Arranjos Institucionais de Políticas Públicas. Brasília: IPEA, 2014.

PIRES, Roberto Rocha C.; GOMIDE, Alexandre de Ávila; AMARAL, Lucas Alves. A Revitalização da Indústria Naval no Brasil Democrático. In: GOMIDE, Alexandre de Ávila; PIRES, Roberto Rocha (Eds.). Capacidades Estatais e Democracia: Arranjos Institucionais de Políticas Públicas. Brasília: IPEA, 2014.

RODRIK, Dani. Industrial Policy for the Twenty-First Century [Online]. Working Paper prepared for UNIDO, 2004. Disponível em: $<$ https://www.sss.ias.edu/files/pdfs/Rodrik/Research/industrialpolicy-twenty-first-century.pdf>. Acesso em: 31 jan. 2017.

SANDLER, Todd; HARTLEY, Keith. Handbook of Defense Economics. New York: Cambridge University Press, 1995. v. 1.

SCHAPIRO, Mario G. Ativismo Estatal e Industrialismo Defensivo: instrumentos e capacidades na política industrial brasileira. In: GOMIDE, Alexandre de Ávila; PIRES, Roberto Rocha (Ed.).

Capacidades Estatais e Democracia: Arranjos Institucionais de Políticas Públicas. Brasília: IPEA, 2014. p. 239-267.

SILVA, Peterson Ferreira. A politica industrial de defesa no Brasil (1999-2014): intersetorialidade e dinâmica de seus principais atores. Tese de doutorado, Instituto de Relações Internacionais, Universidade de São Paulo. São Paulo, 2015.

Artigo recebido em: Outubro/2018

Artigo aprovado em: Novembro/2019

Christiano Cruz Ambros (chrisambros@gmail.com) é agente de desenvolvimento na Secretaria do Desenvolvimento Econômico, Ciência e Tecnologia (SDECT) do Estado do Rio Grande do Sul. Doutor em Ciência Política pela Universidade Federal do Rio Grande do Sul (UFRGS).

\section{Arranjos Institucionais e Política Industrial de Defesa: construção de um modelo analítico}

Resumo. O objetivo deste artigo é propor um modelo analítico para políticas de desenvolvimento da Base Industrial de Defesa (BID), principalmente políticas de aquisição e industriais de defesa, por meio do arcabouço conceitual dos arranjos institucionais. Utilizando-se de diferentes justificativas estratégicas - partindo da garantia da soberania, mas não se limitando a ela -, diversos países buscam desenvolver e consolidar uma indústria de defesa nacional. Aqueles países que se situam na camada intermediária da hierarquia global da indústria de defesa, como o Brasil, enfrentam constrangimentos estruturais para consolidar sua BID, entre eles o trilema da modernização da defesa. Para perpassar esses desafios, os países com BID mais consolidadas empregam uma série de políticas públicas, executadas por diferentes atores políticos e burocráticos e com variadas esferas de impacto. Neste artigo, exploramos as principais características e conceitos das políticas de aquisição e políticas industriais de defesa e avaliamos a literatura de arranjos institucionais enquanto ferramenta analítica, desenvolvendo um modelo de análise capaz de capturar diferentes facetas do fenômeno de forma 
integrada. Espera-se com este modelo contribuir para o avanço dos estudos comparados no campo de pesquisa da Economia de Defesa.

Palavras-chave: Indústria de Defesa; Arranjos Institucionais; Política Industrial de Defesa; Trilema da Modernização de Defesa.

\title{
Institutional Arrangements and Defense Industrial Policy: developing an analytical framework
}

\begin{abstract}
The aim of this article is to propose an analytical model for the Defense Industry Development policies, mainly acquisition policies and industrial policy, through the conceptual framework of institutional arrangements. Using different strategic justifications - from the guarantee of sovereignty, but not limited to it - several countries seek to develop and consolidate a national defense industry. Those countries that are at the middle of the global hierarchy of the defense industry, such as Brazil, face structural constraints to consolidate their defense industry, including the trilemma of defense modernization. To address these challenges, countries with more consolidated industries employ a range of public policies, implemented by different political and bureaucratic actors and with a variety of impact areas. In this article, we explore the main characteristics and concepts of acquisition policies and defense industrial policies and evaluate the literature on institutional arrangements as an analytical tool, developing a model of analysis capable of capturing different facets of the phenomenon in an integrated way. This model is expected to contribute to the advancement of comparative studies in the research field of defense economics.
\end{abstract}

Keywords: Defense Industry; Institutional Arrangements; Defence Industrial Policy; Trilemma of Defense Modernization. 